\title{
A Preliminary Investigation to Establish the Criterion Validity of a Qualitative Scoring System of Limb Alignment during Single Leg Squat and Landing
}

\author{
Lee Herrington ${ }^{1 *}$ and Allan Munro ${ }^{2}$ \\ ${ }^{1}$ Senior Lecturer in Sports Rehabilitation, Directorate of Sport, Exercise and Physiotherapy, University of Salford, UK \\ ${ }^{2}$ Lecturer in Sports Rehabilitation, Division of Rehabilitation Studies, University of Bradford, UK
}

Received: 05 April, 2014; Accepted: 04 July, 2014; Published: 09 July, 2014

*Corresponding author: Lee Herrington PhD MCSP, Directorate of Sport, Exercise and Physiotherapy, Allerton Building, University of Salford, Manchester M6 6PU, United Kingdom, Tel: 00441612952326; Fax: 00441612952395; E-mail: L.C.Herrington@Salford.ac.uk

\begin{abstract}
Objective: The present study aimed to investigate the criterion validity of a novel qualitative assessment scheme to assess limb alignment during single leg loading activities.

Design and setting: Observational laboratory study

Main outcome measures: Performance of 5 participant's single leg squat and hop landing was assessed using 3-D motion capture and the findings of this compared to the qualitative scoring scheme.

Results: The range of percentage of agreement between the qualitative and 3-D score was for all subjects across both tasks 95.6$100 \%$. The kappa measure of agreement was $\mathrm{k}=0.9$ for hop landing and $\mathrm{k}=0.97$ for single leg squat.

Conclusion: The scores generated by the qualitative scoring scheme used showed excellent association with the corresponding data from 3-D motion capture, implying the measurement tool shows criterion validity.
\end{abstract}

Keywords: Assessment; Lower limb; Movement

\section{Introduction}

The presence of abnormal dynamic alignment of the lower limb has been associated with numerous lower limb pathologies [1,2] Within the literature limb alignment control has been assessed using what has been regarded as the "gold standard" 3-D motion capture [2]. These systems although accurate are expensive and assessments time consuming [3], this has led a number of authors to develop qualitative means of assessing lower limb alignment [1,3-7]. The findings of those studies have shown their scoring systems to be both reliable [1,3-7] and valid [3,5] and thus show considerable promise when assessing patients. To date these qualitative scoring systems have either assessed bilateral drop jumps $[3,5,8]$ or single leg squatting $[1,5,7]$, with none assessing single leg landing tasks or using a single system to assess diverse tasks. Ekegren, et al. [5] and Onate, et al. [3] both established the criterion validity of a qualitative scoring scheme (comparing with 3-D motion capture) of drop jump landing, however, no study to date has established the criterion validity of any qualitative scoring system for single leg tasks.

The purpose of this study was to undertake preliminary work to examine the level of agreement and validity of a novel observational movement assessment score and its ability to evaluate trunk and lower limb alignment during two different single leg loading tasks compared to 3-D motion capture. The aim being to assess the validity of the qualitative score acquired during single leg squatting and hop landing against 3-D kinematics.

\section{Method}

\section{Subjects}

The performance of five participants during single leg squat and single leg landing tasks was assessed using 3-D motion assessment and a qualitative scoring system. This group comprised of three male and two female subjects (mean age $20.6 \pm 1.3$ years; height $1.78 \pm 0.1 \mathrm{~m}$; weight $78 \pm 7 \mathrm{~kg}$ ) who gave written informed consent to participate and the project was approved by the host university research and ethics committee. All participants were physically active, participating in at least 3 hours training per week and had no current or previous (in the last 2 years) lower limb, low back or pelvic injuries.

\section{Procedures}

Single Leg Squat (SLS) test task: Participants were asked to take a single leg stance on the force plate, then to squat to at least $45^{\circ}$ knee flexion and no greater than $60^{\circ}$, over a period of five seconds. Knee flexion angle was checked during practice trials using a standard goniometer (Gaiam-Pro) then observed by the same examiner throughout the trials. There was also an electronic counter used to mark the five second period with the first count initiating the movement, the third indicating the lowest point of the squat and the fifth indicating the end. Trials were only accepted if the participant squatted within the desired range of knee flexion [9]. Data was collected from three trials which met the inclusion criteria. 
Single Leg Landing (SLL) task: Participants dropped from a $30 \mathrm{~cm}$ step, standing on the leg to be tested (right in all cases), participants were instructed to hop and land on a mark $30 \mathrm{~cm}$ in front of the step on the force platform. Participants had to ensure the contralateral leg made no contact with any other surface. Participants were required to hold the landing for at least two seconds before stepping off the force plate. Trials were only accepted if the subjects landed on the mark and held the position for 2 seconds [9]. Data was collected from three trials which met the inclusion criteria.

3D analyses: A twelve-camera OQUS (Qualisys, Gothenburg, Sweden) motion analysis system sampling at $100 \mathrm{~Hz}$, and a force platform (AMTI BP400600, USA) sampling at $1000 \mathrm{~Hz}$, was used to collect the kinematic data. Prior to testing reflective markers were attached to the participants at the anterior superior iliac spines, posterior superior iliac spines, iliac crest, greater trochanters, medial and lateral femoral condyles, medial and lateral malleoli, posterior calcanei, and the head of the first, second and fifth metatarsals. These markers were used to define the anatomical reference frame and centres of rotations of the joints. Five rigid plates, each consisting of four non-collinear markers, were secured with elastic bandages on the anterolateral aspect of the thigh, shank and around the pelvis. These rigid bodies were used as tracking markers to track the movement of each segment during the movement trial. The use of a rigid marker set of four non-collinear markers for tracking purposes has previously been shown to be the optimal configuration in comparison to using individual skin markers and other rigid arrays [10]. To track the motion of the thoracic spine, a rigid plate with three attached markers, was attached to the sternum and in order to define an anatomical reference frame for this segment, markers were attached to $\mathrm{C} 7$, the spinous process of the sixth thoracic vertebra (T6), the suprasternal notch and the xiphoid process. The calibrated anatomical systems technique (CAST) was employed to determine the movement of each segment and anatomical significance during the movement trials [11]. A static trial was carried out initially to allow for later identification of the anatomical and tracking markers in the Qualysis software prior to extraction to post-processing software and define the subjects neutral (anatomical) zero position which are referred back to this position. Post-processing calculation of the kinematic and kinetic time series data was conducted using Visual3D motion capture software (Version 4.21, C-Motion Inc., Rockville, MD, USA). Motion and force plate data were filtered using a Butterworth $4^{\text {th }}$ order bi-directional low-pass filter with cut-off frequencies of 12 $\mathrm{Hz}$ for kinematic data and $25 \mathrm{~Hz}$ for force plate data. Three trials were recorded and mean data from the three trials of each task was used for comparison to the qualitative score.

Qualitative assessment: Qualitative assessment of the two tasks was made from digital video footage captured simultaneously during the 3D assessment. A digital video camera (Sony Handycam DCR-HC37) sampling at $25 \mathrm{~Hz}$ was wall mounted at a height of $60 \mathrm{~cm}$ and 10 metres away from the force plates. Digital video footage was recorded at a standard 10x optical zoom throughout each trial in order to standardize the camera position.
A qualitative scoring system was devised by the primary author (LH) based on the previously reported scoring systems of Crossley et al. [1] and Whatman et al. [7]. It involved dichotomous scoring of the movement strategy occurring in individual body regions (arm, trunk, pelvis, thigh, knee, foot). Scoring was defined as a zero for appropriate strategy and one for inappropriate movements, for each region with best overall score being 0 and worst 10 points. The scoring sheet is shown in Table 1 . Typical errors are shown in Table 2. Optimal behaviour involved minimal deviation or body movement from that prescribed, that is arm do not move, trunk is slightly flexed, but held still, pelvis stays in mid position with minimal tilt, thighs stay parallel and approximately vertically oriented, patellae point towards middle of foot and foot demonstrates minimal wobble.

Analysis: A single examiner (LH) (blind to 3-D data) assessed the videos of the single leg squat and single leg landing of each subject; each video was viewed three times at standard speed and then scored using the qualitative scoring sheet. A second investigator (AM) then analysed the findings of qualitative assessment and compared them to those of the 3-D assessment. Prior to viewing the qualitative scores the same investigator (AM) reduced the 3-D kinematic data for each participant and each joint motion, into dichotomous scores $(0=$ alignment/motion of segment/joint within range of normative data; $1=$ alignment/ motion exceeds range of normative data) corresponding to the movement individual segment movement strategy within the qualitative scoring sheet this reflected the method used by Onate et al. [3]. The normative range was based on those reported in the review of Fox et al. [12].

Statistical analysis: To assess the agreement between 3-D score and qualitative score, a kappa statistical analysis was used.

Table 1: Qualitative assessment form.

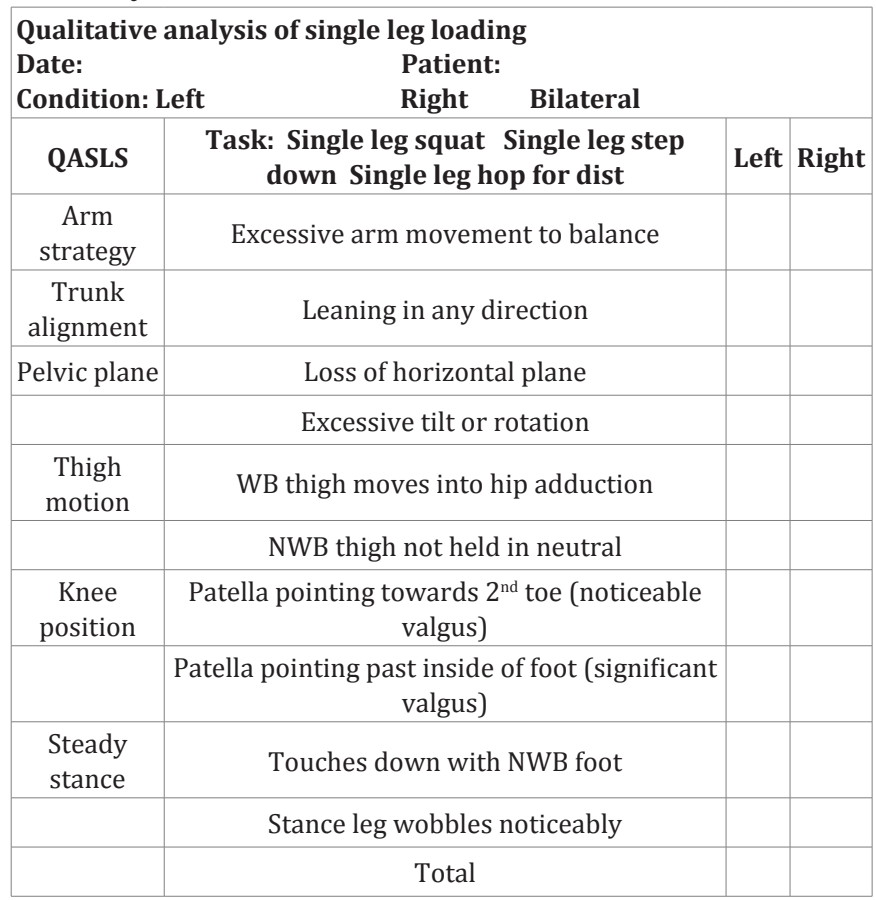


Table 2: Typical errors assessed with qualitative score.

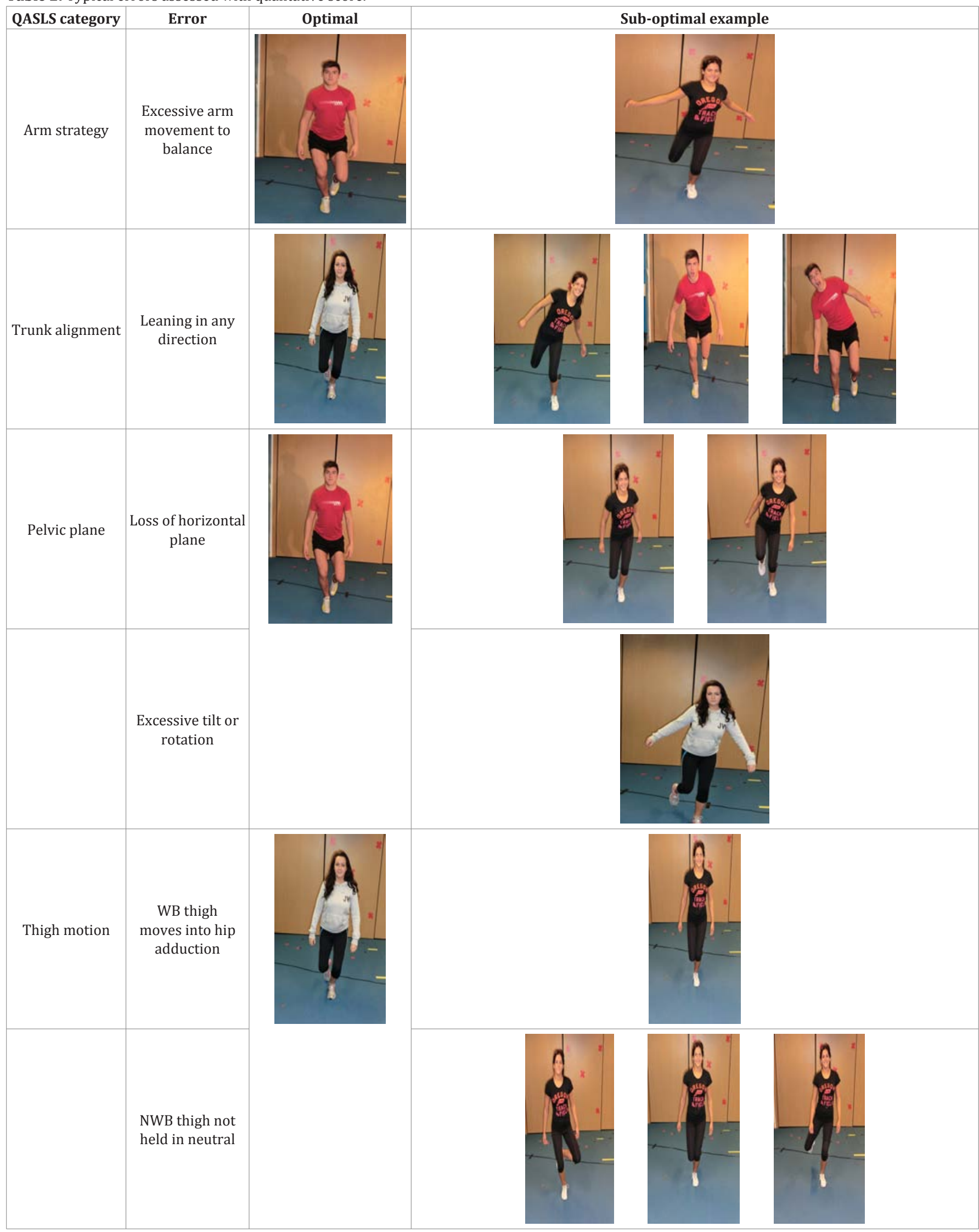

Citation: Herrington L, Munro A (2014) A Preliminary Investigation to Establish the Criterion Validity of a Qualitative Scoring System of Limb Alignment during Single Leg Squat and Landing. J Exerc Sports Orthop 1(2): 1-6. DOI: http://dx.doi.org/10.15226/2374$6904 / 1 / 2 / 00113$ 


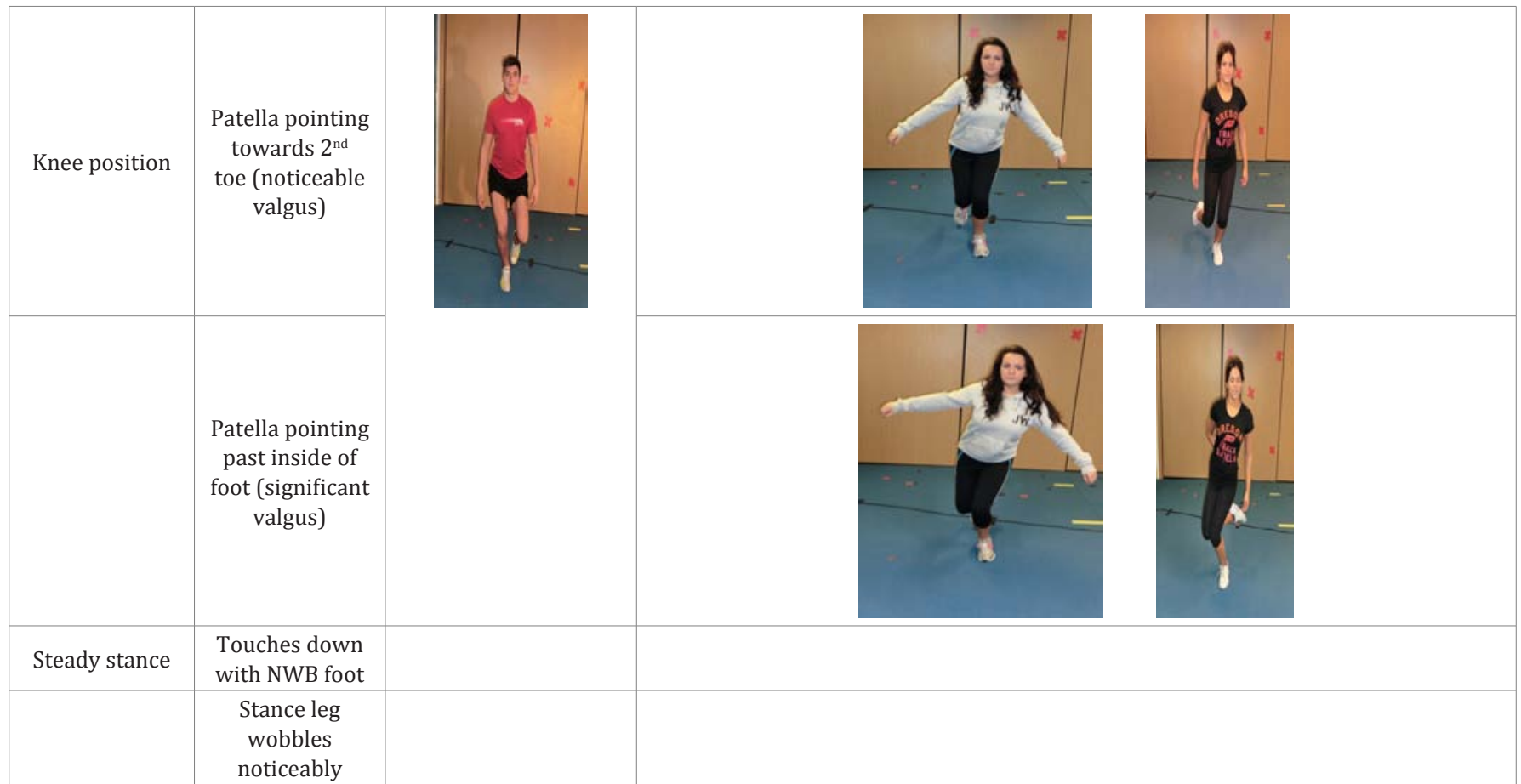

Table 3: Individual comparisons across scoring criteria.

\begin{tabular}{|c|c|c|c|c|c|c|c|c|c|c|c|c|c|c|c|c|c|c|c|c|c|}
\hline Tas & & \multicolumn{20}{|c|}{ Criteria } \\
\hline \multicolumn{2}{|c|}{$\begin{array}{l}\text { Single leg squat } \\
\text { (SLS) }\end{array}$} & \multicolumn{2}{|c|}{ Arm } & \multicolumn{2}{|c|}{ Trunk } & \multicolumn{2}{|c|}{$\begin{array}{l}\text { Pelvis } \\
\text { Frontal }\end{array}$} & \multicolumn{2}{|c|}{$\begin{array}{c}\text { Pelvis } \\
\text { Rotation }\end{array}$} & \multicolumn{2}{|c|}{ WB Hip } & \multicolumn{2}{|c|}{$\begin{array}{l}\text { NWB } \\
\text { Hip }\end{array}$} & \multicolumn{2}{|c|}{$\begin{array}{l}\text { Knee } \\
\text { Valgus } \\
\text { minor }\end{array}$} & \multicolumn{3}{|c|}{$\begin{array}{c}\text { Knee Valgus } \\
\text { Major }\end{array}$} & \multicolumn{2}{|c|}{$\begin{array}{c}\text { WB } \\
\text { Excess } \\
\text { motion }\end{array}$} & $\begin{array}{l}\text { NWB } \\
\text { Touch } \\
\text { down }\end{array}$ \\
\hline Participant & Gender & Q & 3D & Q & 3D & Q & 3D & Q & $3 \mathrm{D}$ & Q & 3D & Q & 3D & Q & 3D & Q & 3D & Q & 3D & $Q$ & $3 \mathrm{D}$ \\
\hline 1 & Male & 0 & 0 & 0 & 0 & 0 & 0 & 0 & 0 & 1 & 1 & 0 & 0 & 0 & 0 & 0 & 0 & 0 & 0 & 0 & 0 \\
\hline 2 & Male & 0 & 0 & 0 & 0 & 1 & 1 & 0 & 0 & 1 & 1 & 0 & 0 & 1 & 1 & 0 & 0 & 0 & 0 & 0 & 0 \\
\hline 3 & Male & 0 & 0 & 1 & 1 & 1 & 1 & 0 & 1 & 1 & 1 & 0 & 0 & 1 & 1 & 1 & 1 & 0 & 0 & 0 & 0 \\
\hline 4 & Female & 0 & 0 & 1 & 1 & 0 & 0 & 1 & 1 & 1 & 1 & 0 & 0 & 1 & 1 & 0 & 0 & 0 & 0 & 0 & 0 \\
\hline 5 & Female & 0 & 0 & 1 & 1 & 1 & 1 & 1 & 0 & 1 & 1 & 0 & 0 & 1 & 1 & 1 & 1 & 0 & 0 & 0 & 0 \\
\hline Tas & & \multicolumn{20}{|c|}{ Criteria } \\
\hline \multicolumn{2}{|c|}{$\begin{array}{l}\text { Single leg land } \\
\text { (SLL) }\end{array}$} & \multicolumn{2}{|c|}{ Arm } & \multicolumn{2}{|c|}{ Trunk } & \multicolumn{2}{|c|}{$\begin{array}{l}\text { Pelvis } \\
\text { Frontal }\end{array}$} & \multicolumn{2}{|c|}{$\begin{array}{c}\text { Pelvis } \\
\text { Rotation }\end{array}$} & \multicolumn{2}{|c|}{ WB Hip } & \multicolumn{2}{|c|}{$\begin{array}{l}\text { NWB } \\
\text { Hip }\end{array}$} & \multicolumn{2}{|c|}{$\begin{array}{l}\text { Knee } \\
\text { Valgus } \\
\text { minor }\end{array}$} & \multicolumn{3}{|c|}{$\begin{array}{c}\text { Knee Valgus } \\
\text { Major }\end{array}$} & $\begin{array}{c}\text { WB } \\
\text { Excess } \\
\text { motion }\end{array}$ & \multicolumn{2}{|c|}{$\begin{array}{c}\text { NWB } \\
\text { Touch } \\
\text { down }\end{array}$} \\
\hline Participant & Gender & $Q$ & 3D & Q & 3D & Q & 3D & Q & 3D & Q & 3D & Q & 3D & Q & 3D & Q & 3D & Q & 3D & Q & $3 \mathrm{D}$ \\
\hline 1 & Male & 0 & 0 & 0 & 0 & 0 & 0 & 0 & 0 & 1 & 1 & 0 & 0 & 0 & 0 & 0 & 0 & 0 & 0 & 0 & 0 \\
\hline 2 & Male & 0 & 0 & 0 & 0 & 1 & 1 & 0 & 0 & 1 & 1 & 0 & 0 & 1 & 1 & 0 & 0 & 1 & 1 & 0 & 0 \\
\hline 3 & Male & 0 & 0 & 1 & 1 & 1 & 1 & 1 & 0 & 1 & 1 & 0 & 0 & 1 & 1 & 1 & 1 & 1 & 1 & 1 & 1 \\
\hline 4 & Female & 0 & 0 & 1 & 1 & 0 & 0 & 1 & 1 & 1 & 1 & 1 & 0 & 1 & 1 & 0 & 0 & 0 & 0 & 1 & 1 \\
\hline 5 & Female & 0 & 0 & 1 & 1 & 1 & 1 & 1 & 1 & 1 & 1 & 1 & 1 & 1 & 1 & 1 & 1 & 1 & 1 & 0 & 0 \\
\hline
\end{tabular}

Citation: Herrington L, Munro A (2014) A Preliminary Investigation to Establish the Criterion Validity of a Qualitative Scoring System of Limb Alignment during Single Leg Squat and Landing. J Exerc Sports Orthop 1(2): 1-6. DOI: http://dx.doi.org/10.15226/2374- 
The scores were also analysed for percentage of exact agreement (PEA) $[\mathrm{PEA}=($ agreed/agreed + disagreed $) \times 100]$. The equation for kappa coefficient $(\kappa)$ is:

$$
\kappa=\frac{\operatorname{Pr}(a)-\operatorname{Pr}(e)}{1-\operatorname{Pr}(e)}
$$

$\operatorname{Pr}(a)$ is the relative observed agreement among raters, $\operatorname{Pr}$ $(e)$ is the hypothetical probability of chance agreement, using the observed data to calculate the probabilities of each observer randomly saying each category. The kappa coefficient was interpreted based on the scale of Landis and Koch [13] with 0.010.2 being slight, $0.21-0.4$; fair, 0.41-0.6; moderate, $0.61-0.8$; good and 0.81-1.0 almost perfect (excellent).

\section{Results}

\section{Single leg squat task}

Average PEA across all cases between the qualitative and 3-D score was $98.4 \%$ (range 96.9-100\%). There were differences in two subjects in scores between qualitative score and 3-D, whilst three showed perfect agreement. The disagreement was a single point for both of these subjects and the disagreement in both cases related to scoring of pelvic rotation (Table 1). The mean kappa measure of agreement across subjects was $\mathrm{k}=0.97(95 \%$ CI 0.86-1.00)

\section{Single leg landing task}

Average PEA across all cases between the qualitative and 3-D score was $97.1 \%$ (range 95.6-100\%). There were differences in two subjects in scores between qualitative score and 3-D, whilst three showed perfect agreement. The disagreement was a single point for both of these subjects and the disagreement in one case related to scoring of pelvic rotation and in the other excessive non weight bearing thigh motion (Table 3). The mean kappa measure of agreement across subjects was $\mathrm{k}=0.9$ (95\% CI 0.83-1.00).

\section{Discussion}

In this pilot study the qualitative scoring system used in this study was shown to have a strong relationship to the kinematic data generated using 3-D motion capture; this was in line with previous studies $[3,5]$ which had examined the relationship of qualitative scoring systems during drop jumping tasks. No previous studies have examined criterion validity of a qualitative scoring system during a single leg loading tasks (single leg squat, single leg hop landing) so comparison to these tasks are not possible.

The qualitative scoring system used was based on those previously reported in the literature which had attempted to analyse single leg squat and had shown good to excellent intra and inter tester reliability $[1,7]$. The scheme incorporated the region criteria similar to that used by both Crossley et al. [1] and Whatman et al. [7], following the assertion from both Onate et al. [3], Chmielewski et al. [4] and Whatman et al. [7] that this increased content validity. Similarly, a dichotomous scale was used when classifying motion within each of the regions which was shown to increase reliability [7]. The scheme used in this study was modified from those studies to also take into account trunk motion which Crossley et al. [1] and Myer et al. [6] regarded as a significant factor in the alteration of lower limb moments.

\section{Conclusion}

Many authors regard 3-D motion analysis as the "gold standard" for assessing dynamic lower limb alignment control $[2,3,8]$ but this is not an option open to most clinicians. The qualitative assessment scheme used in this pilot study has been shown to have strong criterion validity when compared to 3-D motion capture, so may provide an alternate means of assessing dynamic lower limb alignment control for the clinician. Further work though is still required on the tool to assess its reliability and sensitivity to change, on a larger scale, before it is ready to be fully adopted.

\section{References}

1. Crossley KM, Zhang WJ, Schache AG, Bryant A, Cowan SM. Performance on the single leg squat task indicates hip abductor muscle function. Am J Sports Med. 2011; 39(4):866-873.

2. Hewett TE, Myer GD, Ford KR, Heidt RS Jr, Colosimo AJ, McLean $\mathrm{SG}$, et al. Biomechanical measures of neuromuscular control and valgus loading of the knee predict anterior cruciate ligament injury risk in female athletes: a prospective study. Am J Sports Med. 2005; 33(4):492-501.

3. Onate J, Cortes N, Welch C, Van Lunen BL. Expert versus novice interrater reliability and criterion validity of the landing error scoring system. J Sport Rehabil. 2010; 19(1):41-56.

4. Chmielewski TL, Hodges MJ, Horodyski M, Bishop MD, Conrad $\mathrm{BP}$, Tillman SM. Investigation of clinician agreement in evaluating movement quality during unilateral lower extremity functional tasks: a comparison of 2 rating methods. J Orthop Sports Phys Ther. 2007; 37(3):122-129.

5. Ekegren CL, Miller WC, Celebrini RG, Eng JJ, Macintyre DL. Reliability and validity of observational risk screening in evaluating dynamic knee valgus. J Orthop Sports Phys Ther. 2009; 39(9):665-674.

6. Myer GD, Brent JL, Ford KR, Hewett TE. Real-time assessment and neuromuscular training feedback techniques to prevent ACL injury in female athletes. Strength Cond J. 2011; 33(3):21-35.

7. Whatman C, Hing W, Hume P. Physiotherapist agreement when visually rating movement quality during lower extremity functional screening tests. Phys Ther Sport. 2012; 13(2):87-96.

8. Padua DA, Marshall SW, Boling MC, Thigpen CA, Garrett WE Jr, Beutler AI. The Landing Error Scoring System (LESS) Is a valid and reliable clinical assessment tool of jump-landing biomechanics: The JUMP-ACL study. Am J Sport Med. 2009; 37(10):1996-2002.

9. Munro A, Herrington L, Carolan M. Reliability of two-dimensional video assessment of frontal plane dynamic knee valgus during common athletic screening tasks. J Sport Rehabil. 2012; 21(1):7-11.

10. Manal K, McClay I, Stanhope S, Richards J, Galinat B. Comparison of surface mounted markers and attachment methods in estimating tibial rotations during walking: an in vivo study. Gait Posture. 2000; 11(1):38-45.

11. Cappozzo A, Catani F, Leardini A, Benedetti MG, Croce UD. Position and orientation in space of bones during movement: Experimental artefacts. Clin Biomech. 1996; 11(2):90-100. 
12. Fox AS, Bonacci J, McLean SG, Spittle M, Saunders N. What is normal? Female lower limb kinematic profiles during athletic tasks used to examine anterior cruciate ligament injury risk: asystematic review. Sports Med. 2014; 44(6):815-832.
13. Landis JR, Koch GG. The measurement of observer agreement for categorical data. Biometrics. 1977; 33(1):159-174. 